\title{
Risikofaktor Entzündung Rheumatiker-Herzen geraten öfter aus dem Takt
}

\begin{abstract}
Patienten mit rheumatoider Arthritis haben ein deutlich erhöhtes Risiko nicht nur für Herzinfarkte, sondern auch für Vorhofflimmern und Schlaganfall.
\end{abstract}

In den Leitlinien der europäischen Rheumatologen-Gesellschaft EULAR wird bereits empfohlen, Patienten mit rheumatoider Arthritis (RA) jedes Jahr auf kardiovaskuläre Risikofaktoren hin zu untersuchen. Der Grund dafür sind Studien, denen zufolge die Gelenkpatienten ein erhöhtes Risiko für Herzinfarkt und kardiovaskulär bedingten Tod haben. Eine bevölkerungsbasierte Studie aus Dänemark legt nun nahe, das jährliche Screening auch auf Vorhofflimmern auszudehnen. In der Studie trat die Herzrhythmusstörung bei RA-Patienten nämlich um $40 \%$ häufiger auf als in der Allgemeinbevölkerung. Darüber hinaus war auch das Schlaganfallrisiko erhöht, und zwar um rund $30 \%$.

In die Registerstudie einbezogen waren alle Einwohner Dänemarks über 15 Jahre, bei denen vor 1997 weder RA noch Vorhofflimmern oder Schlaganfall bekannt waren. Bis 2009 wurde bei 18247 Personen die Diagnose "rheumatoide Arthritis" gestellt. Die Patienten, zu 70\% Frauen, waren bei der Diagnosestellung im Mittel 59 Jahre alt und wurden danach knapp fünf Jahre weiterbeobachtet.

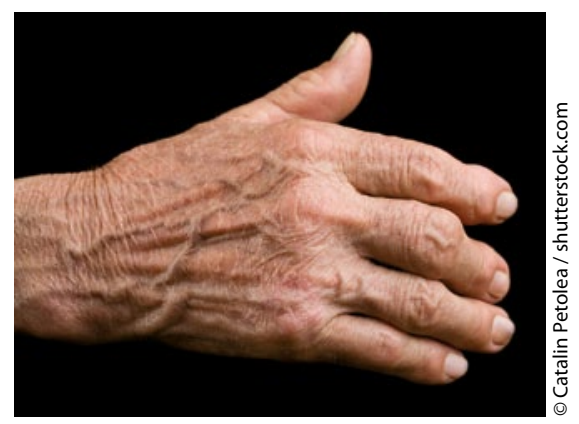

Bei solchen Händen sollten Sie auch an das Herz denken.

\section{Zehn Jahre nach der Diagnose hat} jeder Zwölfte Vorhofflimmern

In diesem Zeitraum wurde bei 156484 Menschen ein Vorhofflimmern neu erkannt, darunter waren 774 RA-Patienten. Das entsprach einer Erkrankungsrate von 8,2 pro 1000 Personenjahren bei den Rheumatikern - im Vergleich zu einer Quote von 6 pro 1000 Personenjahren in der Allgemeinbevölkerung. Einen Schlaganfall erlitten während des Follow-up 165343 Menschen, unter ihnen 718 Rheumapatienten. Bei ihnen wurden damit pro 1000 Personenjahren 7,6 Schlaganfälle registriert, in der Allgemeinbevölkerung waren es nur 5,7.
Besonders ausgeprägt war der Risikoanstieg bei den unter 50-Jährigen: Mit einer RA hatten sie dreimal so häufig ein Vorhofflimmern oder einen Schlaganfall wie ohne. Wenn man die absoluten Ereignisraten betrachtete, fanden sich die größten Unterschiede jedoch bei älteren Menschen mit bzw. ohne RA.

Woher kommt das hohe Flimmerrisiko? RA-Patienten haben ein erhöhtes Herzinsuffizienzrisiko und eine höhere Arteriensteifigkeit, beides etablierte Risikofaktoren für ein Vorhofflimmern. Auch der Gebrauch von Glukokortikoiden und NSAR kann die Arhythmie begünstigen. Nicht zuletzt wird der chronischen Entzündung selbst eine Rolle in der Pathogenese zugeschrieben.

Zum Schlaganfallrisiko von RA-Patienten haben vorausgegangene Studien widersprüchliche Resultate geliefert. Möglicherweise dauert es, so die Spekulation der dänischen Autoren, bis sich der Risikoanstieg bemerkbar macht. Ihrer Studie zufolge lässt sich der Zusammenhang zwischen RA und Insult nicht (allein) mit der erhöhten Vorhofflimmernrate erklären.

Dr. Beate Schumacher II

II Lindhardsen J et al. BMJ 2012;344:e1257

\section{Neue Technologie}

\section{Gentest zur Diabetes-Vorhersage}

\author{
Neue biochemische und genetische \\ Tests der sogenannten Omics-Techno- \\ logie könnten die Vorhersage von \\ Typ-2-Diabetes zukünftig erheblich \\ verbessern.
}

Die Tests liefern einen Überblick über das Erbgut sowie die in den Zellen abgelesenen Gene und die Stoffwechselprodukte eines Patienten.

Dabei könnten sogenannte "Metabolomics-Untersuchungen" erste Stoffwechselstörungen aufdecken. „Dies wäre möglich, lange bevor der Blutzucker auf Dauer an- steigt und zu ersten Schäden führt", so Professor Andreas Fritsche aus Tübingen.

Ein Genomics-Test könnte gleichzeitig alle bisher bekannten mehr als 40 Risikogene für Typ-2-Diabetes erfassen. Es ließen sich zudem Genregulatoren - bestimmte Typen der RNA (sogenannte micro-RNA) - aufspüren, die eine Rolle in der Entstehung des Typ-2-Diabetes spielen könnten.

Bekannte Gene erklären nur etwa zehn Prozent des ererbten Risikos

"Noch steckt die Erforschung von Metabolom und Transkriptom in den Kinderschuhen, und gerade die Aussagekraft der Genomics ist begrenzt", gibt Fritsche zu bedenken. Denn alle bekannten Gene erklären nur etwa zehn Prozent des ererbten Risikos für Typ-2Diabetes. Bei dieser Diabetesform ist das Risiko überwiegend durch den Lebensstil und seine Interaktion mit der genetischen Ausstattung eines Menschen bestimmt.

Die DDG rechnet damit, dass noch einige Jahre vergehen, bis die Techniken verfügbar werden.

Eb II

III Pressemitteilung Deutsche Diabetes Gesellschaft 